\title{
Diversity of Diatrypaceae Species Associated with Dieback of Grapevines in South Africa, with the Description of Eutypa cremea sp. nov.
}

Providence Moyo and Lizel Mostert, Department of Plant Pathology, University of Stellenbosch, Matieland, 7602, South Africa; Christoffel F.J. Spies, Plant Protection Division, ARC Infruitec-Nietvoorbji, Stellenbosch, 7599, South Africa; Ulrike Damm, Senckenberg Museum of Natural History Görlitz, 02806 Görlitz, Germany; and Francois Halleen, ${ }^{\dagger}$ Plant Protection Division, ARC Infruitec-Nietvoorbji, Stellenbosch, 7599, South Africa

\begin{abstract}
Recent studies in grape-growing areas including Australia, California, and Spain have revealed an extensive diversity of Diatrypaceae species on grapevines showing dieback symptoms and cankers. However, in South Africa, little is known regarding the diversity of these species in vineyards. The aim of this study was, therefore, to identify and characterize Diatrypaceae species associated with dieback symptoms of grapevine in South Africa. Isolates were collected from dying spurs of grapevines aged 4 to 8 years old, grapevine wood showing wedge-shaped necrosis when cut in cross section as well as from perithecia on dead grapevine wood. The collected isolates were identified based on morphological characters and phylogenetic analyses of the internal transcribed spacer region (ITS) and $\beta$-tubulin gene. Seven Diatrypaceae species were identified on grapevine, namely Cryptovalsa ampelina, C. rabenhorstii, Eutypa consobrina,

E. lata, E. cremea sp. nov., Eutypella citricola, and E. microtheca. The dying spurs yielded the highest diversity of species when compared with the wedge-shaped necrosis and/or perithecia. C. ampelina was the dominant species in the dying spurs, followed by E. citricola, whereas E. lata was the dominant species isolated from the wedge-shaped necroses and perithecia. These results confirm $E$. lata as an important grapevine canker pathogen in South Africa, but the frequent association of C. ampelina with spur dieback suggests that this pathogen plays a more prominent role in dieback than previously assumed. In some cases, more than one species were isolated from a single symptom, which suggests that interactions may be occurring leading to decline of grapevines. C. rabenhorstii, E. consobrina, E. citricola, E. microtheca, and E. cremea are reported for the first time on grapevine in South Africa.
\end{abstract}

An increase in the number of Diatrypaceae species isolated from grapevine cankers has recently been reported from different grapegrowing countries worldwide (Díaz et al. 2011; Luque et al. 2012; Paolinelli-Alfonso et al. 2015; Pitt et al. 2010; Rolshausen et al. 2014; Trouillas and Gubler 2004; Trouillas et al. 2010, 2011). For many decades, canker diseases on grapevine have been attributed to the Diatrypaceae species, Eutypa lata (Pers.) Tul. \& C. Tul (Carter 1988; Ferreira 1987; Moller and Kasimatis 1978). In Eutypa dieback, grapevines become infected when ascospores of $E$. lata enter fresh wounds, resulting from pruning or mechanical damage. Ascospores, which are the primary form of inoculum of E. lata, are produced from mature perithecia occurring within stroma found on dead wood, during rainfall periods. The ascospores germinate in xylem vessels and the fungus subsequently colonizes the wood (Moller and Carter 1965; Moller and Kasimatis 1978).

Recent studies, however, have reported the existence of at least 17 Diatrypaceae species from cankers on grapevines. These species include Cryptosphaeria pullmanensis Glawe, Cryptovalsa ampelina (Nitschke) Fuckel, Cryptovalsa rabenhorstii (Nitschke) Sacc., Diatrype oregonensis (Wehm.) Rappaz, D. stigma (Hoffm.) Fr., Diatrype whitmanensis J.D. Rogers \& Glawe, Diatrypella verrucaeformis (Ehrh.) Nitschke, Diatrypella vulgaris Trouillas, W.M. Pitt \& Gubler, Eutypa laevata (Nitschke) Sacc., Eutypa leptoplaca (Mont.) Rappaz, Eutypella citricola Speg., Eutypella leprosa (Pers. ex Fr.) Berl., Eutypella microtheca Trouillas, W.M. Pitt \& Gubler, Eutypella scoparia (Schwein.: Fr.) Ellis \& Everh., and Eutypella vitis (Schwein.: Fr.) Ellis \& Everh. (Catal et al. 2007; Díaz et al. 2011; Luque et al. 2012; Mostert et al. 2004; Paolinelli-Alfonso et al. 2015; Pitt et al. 2010; Rolshausen et al. 2006, 2014; Schilder et al. 2003; Trouillas and Gubler 2004; Trouillas et al. 2010, 2011). Studies have even reported that some of the newly reported species including C. ampelina, E. citricola, E. microtheca, E. laevata, an unidentified Eutypa sp., and an unidentified

${ }^{\dagger}$ Corresponding author: F. Halleen; E-mail: halleenf@arc.agric.za

Accepted for publication 29 August 2017.

C 2018 The American Phytopathological Society
Diatrypella sp. occurred more abundantly and were more widely distributed geographically than E. lata, which was originally thought to be the most abundant and widely distributed species (Pitt et al. 2010; Rolshausen et al. 2014; Trouillas et al. 2011). These findings raised questions as to whether these newly discovered Diatrypaceae fungi are a threat to the sustainability of the grapevine industry and have led researchers to investigate their role as canker pathogens and the need to take them into account in global efforts to manage canker diseases of grapevine. Results of pathogenicity trials of several of these Diatrypaceae taxa on grapevine have further led researchers to postulate that E. lata is not the sole Diatrypaceae species associated with grapevine cankers and dieback symptoms, but several species of Diatrypaceae are also involved in the trunk disease complex as canker pathogens (Jordan and Schilder 2005; Pitt et al. 2013; Rolshausen et al. 2014; Trouillas and Gubler 2010).

The trunk disease complex is composed of grapevine canker diseases, which include Eutypa dieback and diseases caused by species in the Botryosphaeriaceae and Diaporthales. Trunk diseases are responsible for the shortened lifespan of vineyards and severe losses as a result of vineyard re-establishment and reduced yields throughout the world. Symptoms include cankers and other dieback symptoms such as stunted shoot, shortened internodes, bud mortality, leaf chlorosis, sectorial wood necrosis, shoot dieback, and cane bleaching.

Similar to other grape-growing countries, canker pathogens are important in South Africa. Recently, poor budburst and spur dieback in Sauvignon blanc and Cabernet Sauvignon vineyards, including those as young as 4 years old, have been observed in Western Cape Province of South Africa. Spurs of the affected vines either produce weak shoots, which die soon after bud break, or the spurs do not produce new shoots at all in spring. These observations are disturbing considering young vineyards are also affected. The question that arises concerns the extent to which Diatrypaceae are involved in the phenomenon.

Although studies in other countries have provided evidence of the occurrence and pathogenicity of several diatrypaceous fungi on grapevine, the information presently available about the occurrence and identity of the species of Diatrypaceae associated with dieback of grapevine in South Africa is still limited. In fact, only four Diatrypaceae species have been isolated from grapevine, namely E. lata, C. ampelina, 
an unidentified Eutypa sp., and a Eutypella species (Mostert et al. 2004; Safodien et al. 2005). The overall aim of this study was, therefore, to identify Diatrypaceae species associated with dieback of grapevines. The first objective of this study was to determine whether Diatrypaceae species are associated with dying spurs in Cabernet Sauvignon and Sauvignon blanc vineyards severely affected by poor budburst and spur dieback. The second objective of the study was to identify Diatrypaceae species associated with the wedge-shaped necrosis on numerous wine grape cultivars showing dieback symptoms, in Western Cape Province of South Africa. The third objective was to carry out surveys for perithecia of species of Diatrypaceae on grapevine in South Africa.

\section{Materials and Methods}

Sampling and isolate collection. Four- to eight-year-old Sauvignon blanc and Cabernet Sauvignon vineyards were sampled in 2013 and 2014 to determine whether Diatrypaceae species were associated with dying spurs. Sampling was carried out in different locations in Western Cape Province to represent areas with different environmental conditions, namely Stellenbosch, Grabouw, Constantia, Durbanville, and Robertson. Sampling was conducted in 19 Sauvignon blanc and 17 Cabernet Sauvignon vineyards. Ten dying spurs were collected from each vineyard, individually placed in bags, and taken to the laboratory for processing. In the laboratory, spurs were split open through the pruning wounds to reveal internal symptoms and were then surface sterilized by submerging in $70 \%$ ethanol for $30 \mathrm{~s}, 2.5 \%$ sodium hypochlorite for $2 \mathrm{~min}$, and again in $70 \%$ ethanol for another $30 \mathrm{~s}$. Subsequently, wood pieces were taken from different necrotic areas as well as from the border between live and dead tissue at the pruning wound and plated onto potato dextrose agar (PDA-C; Biolab, Midrand, South Africa) plates containing chloromycetin ( $250 \mathrm{mg} /$ liter). Plates were incubated at $24^{\circ} \mathrm{C}$, exposed to approximately $12 \mathrm{~h}$ of day light and $12 \mathrm{~h}$ of darkness, and inspected daily for fungal growth for 4 weeks. Isolates of presumed Diatrypaceae species were transferred onto new PDA-C plates for further identification.

To identify Diatrypaceae species associated with wedge-shaped cankers, vineyards were selected on the basis of the presence of dieback symptoms, which included dying spurs, stunted shoots, shortened internodes, dwarfed leaves with tattered margins, and cankers. Cordons and trunks of such vines were cut in cross section and wood showing the wedge-shaped necrosis was then taken to the laboratory for isolations. Samples were collected from 10 cultivars, namely Cabernet Sauvignon, Chardonnay, Chenin blanc, Merlot, Pinot noir, Pinotage, Sauvignon blanc, Semillon, Shiraz, and Viogner. Sampling was done in vineyards aged $\geq 10$ years old, located in nine different locations in Western Cape Province. Isolations were carried out by cutting small wood pieces from the border between live and dead tissue of the wedge-shaped necrosis and plating onto PDA-C as described above.

Dead grapevine wood with black, charcoal-like stroma with fruiting bodies resembling those of E. lata was also collected. Depending on availability of diseased wood, one to 10 samples per vineyard block were randomly collected from the different sampling areas. Isolations from collected samples were achieved according to Trouillas et al. (2010). The stromata were sliced open, under a Nikon SMZ 1500 stereo microscope, using a scalpel to reveal perithecial contents. A drop of sterile water was then added to the opened perithecia. Perithecial contents were then collected with a needle, mounted in water on a microscopic slide, and examined under a light microscope (Nikon Y-TV55) for morphological identification. By pipetting, the perithecial contents on the slides were mixed with $50 \mu \mathrm{l}$ of sterile water and transferred onto water agar (WA; Biolab, Midrand, South Africa) plates. Single germinated ascospores were transferred to PDA-C plates within $48 \mathrm{~h}$ and the plates were incubated at $24^{\circ} \mathrm{C}$ for 15 to 21 days. Thereafter, fungal identification was carried out.

Morphological characterization of sexual morphs. This technique was used to characterize isolates of species producing fruiting bodies on grapevine wood. Perithecial contents were collected as described above and mounted in $10 \%$ lactic acid, examined microscopically, and images were captured with a Nikon DS-Ri2 camera on a Nikon Y-TV55 light microscope at 1,000 $\times$ magnification. Images of stromata were captured using the Nikon DS-Ri2 camera on a Nikon SMZ 1500 stereo microscope. Measurements were made for two or three representative samples of each species; $5 \%$ and $95 \%$ confidence intervals were calculated from the measurements of 50 ascospores, 20 asci (length = spore bearing part and width $=$ width at the widest point), and 10 perithecia (diameter). Characteristics such as morphology of perithecia, asci, and ascospores; number of ascospores per ascus, as well as color of ascospores were noted for each species as described by Rappaz (1987), Glawe and Rogers (1984), and Trouillas et al. (2011).

Morphological and cultural characterization of asexual morphs. For characterization of the asexual states, one or two isolates per species were characterized, depending on the sporulation of the isolates. Three PDA-C plates per isolate were incubated at $24^{\circ} \mathrm{C}$ for 30 days and visual observations of the colony color were made every 3 days. The conidia size from each PDA-C plate was measured and the average conidia sizes of the plates, on which the respective isolate sporulated, was calculated.

DNA isolation, amplification, and sequencing of fungal isolates. DNA was extracted from actively growing cultures using the method described by Damm et al. (2008). Because C. ampelina and E. lata were anticipated to be the most common species, all isolates were first subjected to amplification using species-specific primers to detect these species. The species-specific primer pair, Camp1/Camp2R designed by Luque et al. (2006), was used to detect $C$. ampelina, while the primer pair EL1/EL4 (Catal et al. 2007) was used for the detection of E. lata. A touch-down PCR protocol was used for the amplification of $C$. ampelina and was carried out in a $25-\mu l$ reaction containing the following end concentrations: $1 \times$ PCR buffer, $1 \mathrm{mM} \mathrm{MgCl} 2,0.2 \mu \mathrm{M}$ of each deoxyribonucleotide triphosphates (dNTPs), $1 \mathrm{mM}$ of each primer, and $0.65 \mathrm{U}$ Taq polymerase. The touch-down PCR protocol consisted of two phases: The first phase included an initial denaturing at $94^{\circ} \mathrm{C}$ for $5 \mathrm{~min}$, followed by 20 cycles of denaturation at $94^{\circ} \mathrm{C}$ for $30 \mathrm{~s}$, annealing at $68^{\circ} \mathrm{C}$ for $30 \mathrm{~s}$, and extension at $72^{\circ} \mathrm{C}$ for $30 \mathrm{~s}$. Phase 2 consisted of 10 cycles of $94^{\circ} \mathrm{C}$ for $30 \mathrm{~s}, 66^{\circ} \mathrm{C}$ for $30 \mathrm{~s}, 72^{\circ} \mathrm{C}$ for $30 \mathrm{~s}$, and a final extension step at $72^{\circ} \mathrm{C}$ for $5 \mathrm{~min}$. The EL1/EL4 PCR reaction was performed in a total volume of $25 \mu$ l consisting of $1 \times$ PCR buffer, $3.5 \mathrm{mM} \mathrm{MgCl}_{2}, 0.8 \mathrm{mM}$ dNTPs, $0.5 \mu \mathrm{M}$ of each primer, 0.65 U Taq Polymerase (Bioline, U.S.A.), and $1 \mu$ l DNA template. PCR amplification was conducted using the following thermal regime: initial denaturing for 2 min at $94^{\circ} \mathrm{C} ; 35$ cycles of denaturing at $94^{\circ} \mathrm{C}$ for $1 \mathrm{~min}$, followed by annealing at $62^{\circ} \mathrm{C}$ for $30 \mathrm{~s}$, elongation at $72^{\circ} \mathrm{C}$ for $1 \mathrm{~min}$; final extension at $72^{\circ} \mathrm{C}$ for $5 \mathrm{~min}$.

For isolates in which amplification could not be obtained using species-specific primers, the internal transcribed spacer regions (ITS1 and ITS2) and the 5.8S ribosomal RNA gene were amplified using primers ITS1/ITS4 (White et al. 1990). Twenty isolates of $C$. ampelina and 25 isolates of E. lata, randomly chosen, were also included in this PCR to verify specificity of the species-specific primers. Amplification and sequencing of the ITS region was performed as described by Moyo et al. (2016). Identification of the isolates was based on subjecting the ITS sequence data to the megablast function of the National Center for Biotechnology Information's (NCBI) GenBank nucleotide database (www.ncbi.nlm.nih.gov). Depending on the number of isolates identified by the BLAST search, up to 11 representative isolates of each species, including E. lata and C. ampelina, were selected for amplification of the partial $\beta$-tubulin gene. The partial $\beta$-tubulin gene was amplified and sequenced using the primer set $\mathrm{Bt} 2 \mathrm{a} / \mathrm{Bt} 2 \mathrm{~b}$ (Glass and Donaldson 1995) as described by Moyo et al. (2016).

Phylogenetic analysis. The phylogenetic analyses of the individual ITS and $\beta$-tubulin sequences, as well as of the combined dataset (ITS and $\beta$-tubulin), were performed using maximum likelihood (ML) and Bayesian analyses. The ITS and $\beta$-tubulin sequences, respectively, of representative isolates obtained in this study were aligned with sequences of Diatrypaceae retrieved from GenBank (Table 1) as well as the outgroup Hypoxylon fragiforme. Sequences were aligned with MAFFT v7.017 (Katoh et al. 2002) in Geneious v8.1 (http://www.geneious.com; Kearse et al. 2012) using the default parameters. The alignments were run through Gblocks v0.91b, using default parameters (Castresana 2000) to exclude poorly aligned positions from subsequent phylogenetic inferences. The concatenated alignment was deposited in TreeBASE under study number S20662 (http://purl.org/phylo/treebase/phylows/study/TB2:S20662). 
Maximum likelihood analyses were performed using PhyML (Guindon and Gascuel 2003) in Geneious v8.1 under the general time reversible (GTR) model. Both the proportion of invariable sites and gamma distribution parameter were estimated and bootstrap support values were calculated from 1,000 replicates. Clades with bootstrap support $\geq 70 \%$ were considered significant (Hillis and Bull 1993). Bayesian analyses were done with Mr Bayes v3.2.2 (Huelsenbeck and Ronquist 2001) using the Markov Chain Monte Carlo (MCMC) method. Four MCMC chains were run simultaneously and trees were saved every 100th generation. The first $25 \%$ of generated trees were discarded as the burn-in phase of the analyses. Posterior probabilities were assigned after a 50\% majority-rule. Clades with Bayesian posterior probability $\geq 95 \%$ were considered significant (Alfaro et al. 2003).

\section{Results}

Sampling and isolate collection. A total of 360 dying spurs (Fig. 1A) were collected in this study, with 190 collected from Sauvignon blanc and 170 from Cabernet Sauvignon vineyards. Isolations were performed from different symptoms observed inside the dying spurs (Fig. 1B to F). Subsequently, 68 (36\%) and 71 (42\%) spurs collected from Sauvignon blanc and Cabernet Sauvignon, respectively, yielded Diatrypaceae isolates. Two hundred and ninety-six samples showing wedge-shaped necrosis (Fig. 1G) were collected from vineyards and $72 \%$ of these samples yielded Diatrypaceae isolates. A total of 81 grapevine wood pieces with perithecia of Diatrypaceae species were collected from vineyards in Western Cape Province.

Identification of Diatrypaceae isolates. Maximum likelihood and Bayesian analyses of the individual ITS and $\beta$-tubulin sequences, as well as of the combined data set, generated trees with similar topology with regards to the clades/subclades representing species isolated in this study. The ML tree of the combined dataset is presented in Figure 2 with ML bootstrap support values and Bayesian posterior probability scores at the nodes. In this tree, isolates obtained in this study were distinguished as belonging to seven species, residing in three

Table 1. List of Diatrypaceae isolates collected in this study and reference strains from GenBank, used for phylogenetic analyses

\begin{tabular}{|c|c|c|c|c|c|}
\hline \multirow[b]{2}{*}{ Species } & \multirow[b]{2}{*}{ Host } & \multirow[b]{2}{*}{ Origin } & \multirow[b]{2}{*}{ Strain number } & \multicolumn{2}{|c|}{ GenBank number } \\
\hline & & & & ITS & $\beta$-tubulin \\
\hline Cryptosphaeria ligniota & Populus tremula & Switzerland & CBS 273.87 & KT425233 & KT425168 \\
\hline Cryptosphaeria ligniota & Populus tremuloides & Colorado, U.S.A. & ATCC46315 & KT425234 & KT425169 \\
\hline Cryptosphaeria multicontinentalis & Populus balsamifera subsp. trichocarpa & California, U.S.A. & DSIERRA600 & KT425184 & KT425119 \\
\hline Cryptosphaeria multicontinentalis & Populus balsamifera & Australia & NSW03PO & KT425237 & KT425172 \\
\hline Cryptosphaeria multicontinentalis & Populus sp. & Oregon, U.S.A. & OREG100 & KT425188 & KT425123 \\
\hline Cryptosphaeria pullmanensis & Populus trichocarpa & Washington, U.S.A. & ATCC52655 & KT425235 & KT425170 \\
\hline Cryptosphaeria pullmanensis & Populus nigra 'italica' & California, U.S.A. & DWIN100 & GQ293930 & GQ294015 \\
\hline Cryptosphaeria subcutanea & Salix borealis & Norway & CBS 240.87 & KT425232 & KT425167 \\
\hline Cryptosphaeria subcutanea & Salix myrsinifolia & Norway & DSUB100A & KT425189 & KT425124 \\
\hline Cryptovalsa ampelina & Fraxinus latifolia & California, U.S.A. & DMO100 & GQ293908 & GQ293978 \\
\hline Cryptovalsa ampelina & Vitis vinifera & New South Wales, Australia & HVVIT04 & HQ692558 & HQ692459 \\
\hline Cryptovalsa ampelina & Vitis vinifera & Robertson, WC, South Africa & STEU 8113 & KY111659 & KY111618 \\
\hline Cryptovalsa ampelina & Vitis vinifera & Robertson, WC, South Africa & STEU 8114 & KY111660 & KY111619 \\
\hline Cryptovalsa ampelina & Vitis vinifera & Robertson, WC, South Africa & STEU 8115 & KY111661 & KY111620 \\
\hline Cryptovalsa ampelina & Vitis vinifera & Stellenbosch, WC, South Africa & STEU 8116 & KY111662 & KY111621 \\
\hline Cryptovalsa ampelina & Vitis vinifera & Paarl, WC, South Africa & STEU 8117 & KY111663 & KY111622 \\
\hline Cryptovalsa ampelina & Vitis vinifera & Constantia, WC, South Africa & STEU 8118 & KY111664 & KY111623 \\
\hline Cryptovalsa ampelina & Vitis vinifera & Riebeek-Wes, WC, South Africa & STEU 8119 & KY111665 & KY111624 \\
\hline Cryptovalsa ampelina & Vitis vinifera & Durbanville, WC, South Africa & STEU 8120 & KY111666 & KY111625 \\
\hline Cryptovalsa ampelina & Vitis vinifera & Stellenbosch, WC, South Africa & STEU 8121 & KY111667 & KY111626 \\
\hline Cryptovalsa ampelina & Vitis vinifera & Robertson, WC, South Africa & STEU 8122 & KY111668 & KY111627 \\
\hline Cryptosphaeria rabenhorstii & Vitis vinifera & Western Australia & WA07CO & HQ692620 & HQ692522 \\
\hline Cryptosphaeria rabenhorstii & Vitis vinifera & Western Australia & WA08CB & HQ692619 & HQ692523 \\
\hline Cryptosphaeria rabenhorstii & Vitis vinifera & Stellenbosch, WC, South Africa & STEU 8112 & KY111628 & KY111607 \\
\hline Diatrype brunneospora & Acacia longofora subsp. sophorae & Australia & CNP01 & HM581946 & HQ692478 \\
\hline Diatrype oregonensis & Quercus kelloggii & California, U.S.A. & DPL200 & GQ293940 & GQ293999 \\
\hline Diatrype stigma & Quercus sp. & Irish Republic & CBS 211.87 & AJ302438 & - \\
\hline Diatrypella verruciformis & Quercus sp. & California, U.S.A. & DCH500 & GQ293926 & GQ293991 \\
\hline Diatrypella vulgaris & Citrus paradisi & New South Wales, Australia & HVGRF03 & HQ692590 & HQ692505 \\
\hline Diatrypella vulgaris & Vitis vinifera & New South Wales, Australia & CG8 & HQ692595 & HQ692502 \\
\hline Eutypa consobrina & Arundo donax & Almeria, Spain & F091,961 & AJ302447 & - \\
\hline Eutypa consobrina & Vitis vinifera & Grabouw, WC, South Africa & STEU 8092 & KY111651 & KY111596 \\
\hline Eutypa cremea & Vitis vinifera & Bonnievale, WC, South Africa & STEU 8081 & KY111655 & KY111597 \\
\hline Eutypa cremea & Vitis vinifera & Durbanville, WC, South Africa & STEU 8082 & KY111656 & KY111598 \\
\hline Eutypa cremea & Vitis vinifera & Constantia, WC, South Africa & STEU 8083 & KY111657 & KY111599 \\
\hline Eutypa cremea & Vitis vinifera & Darling, WC, South Africa & STEU 8084 & KY111642 & KY111600 \\
\hline Eutypa cremea & Vitis vinifera & Slanghoek, WC, South Africa & STEU 8085 & KY111658 & KY111601 \\
\hline Eutypa cremea & Vitis vinifera & Robertson, WC, South Africa & STEU 8086 & KY111645 & KY111602 \\
\hline Eutypa cremea & Vitis vinifera & Constantia, WC, South Africa & STEU 8087 & KY111646 & KY111603 \\
\hline Eutypa cremea & Vitis vinifera & Stellenbosch, WC, South Africa & STEU 8088 & KY111647 & KY111604 \\
\hline Eutypa cremea & Vitis vinifera & Constantia, WC, South Africa & STEU 8089 & KY111648 & KY111605 \\
\hline Eutypa cremea & Vitis vinifera & Constantia, WC, South Africa & STEU 8090 & KY111649 & KY111587 \\
\hline Eutypa cremea & Vitis vinifera & Hermanus, WC, South Africa & STEU 8091 & KY111650 & KY111606 \\
\hline Eutypa cremea & Arundo donax & France & CBS 286.87 & AY 684225 & AY684203 \\
\hline Eutypa crustata & Ulmus sp. & France & CBS 210.87 & AJ302448 & DQ006968 \\
\hline Eutypa laevata & Salix sp. & Switzerland & CBS 291.87 & $\begin{array}{l}\text { HM164737 } \\
\text { (Continued }\end{array}$ & $\begin{array}{r}\text { HM164771 } \\
\text { n next page) }\end{array}$ \\
\hline
\end{tabular}


genera, namely Eutypa, Eutypella, and Cryptovalsa. Eight isolates clustered as a strongly supported group (100\%/1.00, ML bootstrap support and Bayesian posterior probability scores) with $E$. citricola isolates. Ten isolates grouped with strong support (99\%/1.00) with C. ampelina isolates obtained from grapevine and Oregon ash in Australia and California, respectively. Five isolates clustered with E. microtheca $(74 \% / 0.94)$ isolates from Australia, whereas one isolate grouped with strong support (100\%/1.00) with $C$. rabenhorstii isolates obtained from grapevine in Australia. Five isolates clustered with strong support (99\%/1.00) with $E$. lata isolates from California and Australia. One isolate grouped with a Eutypa consobrina (Mont.) Rappaz isolate with 100\%/1.00 support. Eleven isolates grouped with the French isolate CBS 286.87 from Arundo donax, designated as E. leptoplaca. This group represents a previously misidentified taxon, which is closely related to Eutypa tetragona (Duby) Sacc. The isolate CBS 286.87 and the 11 isolates obtained in this study, being phylogenetically distinct from other E. leptoplaca isolates, indicate an undescribed species.
Taxonomy. Cryptovalsa ampelina (Nitschke) Fuckel, Symbolae Mycologicae, Beiträge zur Kenntnis der Rheinischen Pilze: 212, 1870 (Fig. 3). Stromata poorly developed and embedded in bark and/or wood. Perithecia globose to ovoid, (439-) 456 to 862 (-941) $\mu \mathrm{m}$ diam., necks infrequently observed, protruding singly or in groups. Asci polysporous, clavate, long stipitate, with an apical invagination, (64-) 73 to $140(-147) \times(8-) 9$ to $13(-14) \mu \mathrm{m}$. Ascospores allantoid, pale brown, (7-) 8 to $12(-14) \times 2$ to $3 \mu \mathrm{m}$. Colonies are white and the underside is cream on PDA-C. Conidia were not observed.

Material examined. South Africa, Western Cape Province, Durbanville, on dead wood of Vitis vinifera, 20 June 2013, P. Moyo, culture number STEU 8120

Notes. A higher maximum ascus length was observed in our study compared with that reported by Trouillas et al. (2011) and Mostert et al. (2004) of $135.80 \mu \mathrm{m}$ and $125 \mu \mathrm{m}$, respectively.

Eutypa cremea Moyo, F. Halleen, L. Mostert, sp. nov., MycoBank MB 819824 (Fig. 4).

Table 1. (Continued from previous page)

\begin{tabular}{|c|c|c|c|c|c|}
\hline \multirow[b]{2}{*}{ Species } & \multirow[b]{2}{*}{ Host } & \multirow[b]{2}{*}{ Origin } & \multirow[b]{2}{*}{ Strain number } & \multicolumn{2}{|c|}{ GenBank number } \\
\hline & & & & ITS & $\beta$-tubulin \\
\hline Eutypa lata & Vitis vinifera & California, U.S.A. & EAMS100 & HM164730 & HM164764 \\
\hline Eutypa lata & Populus nigra 'italica' & South Australia & SAPN01 & HQ692616 & HQ692500 \\
\hline Eutypa lata & Vitis vinifera & Grabouw, WC, South Africa & STEU 8093 & KY111652 & KY111613 \\
\hline Eutypa lata & Vitis vinifera & Somerset West, WC, South Africa & STEU 8094 & KY111653 & KY111614 \\
\hline Eutypa lata & Vitis vinifera & Barrydale, WC, South Africa & STEU 8095 & KY111643 & KY111615 \\
\hline Eutypa lata & Vitis vinifera & Grabouw, WC, South Africa & STEU 8096 & KY111654 & KY111616 \\
\hline Eutypa lata & Vitis vinifera & Grabouw, WC, South Africa & STEU 8097 & KY111644 & KY111617 \\
\hline Eutypa lata var. aceri & Acer campestre & France & CBS 217.87 & HM164734 & HM164768 \\
\hline Eutypa lejoplaca & Acer pseudoplatanus & Switzerland & $020202-5$ & AY684221 & AY684196 \\
\hline Eutypa leptoplaca & Frangula alnus & Switzerland & CBS 287.87 & AY684226 & AY684204 \\
\hline Eutypa leptoplaca & Cyssus hypoglauca & Australia & CBS 288.87 & AY684227 & AY684205 \\
\hline Eutypa maura & Acer pseudoplatanus & Switzerland & CBS 219.87 & AY684224 & DQ006967 \\
\hline Eutypa petrakii var. petrakii & Prunus spinosa & Switzerland & CBS 244.87 & HM164735 & HM164769 \\
\hline Eutypa sparsa & Populus sp. & Switzerland & $3802-3 \mathrm{a}$ & AY684200 & AY684219 \\
\hline Eutypa tetragona & Laburnum alpinum & Switzerland & $190802-3$ & AJ684223 & AY684202 \\
\hline Eutypa tetragona & Sarothamnus scoparius & France & CBS 284.87 & DQ006923 & DQ006960 \\
\hline Eutypella australiensis & Acacia longofora subsp. sophorae & Australia & CNP03 & HM581945 & HQ692479 \\
\hline Eutypella cerviculata & Alnus glutinosa & Switzerland & CBS 221.87 & AJ302468 & - \\
\hline Eutypella citricola & Citrus paradisi & New South Wales, Australia & HVGRF01 & HQ692589 & HQ692521 \\
\hline Eutypella citricola & Citrus sinensis & New South Wales, Australia & HVOT01 & HQ692581 & HQ692509 \\
\hline Eutypella citricola & Vitis vinifera & New South Wales, Australia & HVVIT07 & HQ692579 & HQ692512 \\
\hline Eutypella citricola & Vitis vinifera & Constantia, WC, South Africa & STEU 8098 & KY111634 & KY111588 \\
\hline Eutypella citricola & Vitis vinifera & Stellenbosch, WC, South Africa & STEU 8099 & KY111637 & KY111589 \\
\hline Eutypella citricola & Vitis vinifera & Stellenbosch, WC, South Africa & STEU 8100 & KY111638 & KY111590 \\
\hline Eutypella citricola & Vitis vinifera & Worcester, WC, South Africa & STEU 8102 & KY111635 & KY111591 \\
\hline Eutypella citricola & Vitis vinifera & Grabouw, WC, South Africa & STEU 8103 & KY111639 & KY111592 \\
\hline Eutypella citricola & Vitis vinifera & Constantia, WC, South Africa & STEU 8104 & KY111636 & KY111593 \\
\hline Eutypella citricola & Vitis vinifera & Grabouw, WC, South Africa & STEU 8105 & KY111640 & KY111594 \\
\hline Eutypella citricola & Vitis vinifera & Grabouw, WC, South Africa & STEU 8106 & KY111641 & KY111595 \\
\hline Eutypella cryptovalsoidea & Ficus carica & New South Wales, Australia & HVFIG02 & HQ692573 & HQ692524 \\
\hline Eutypella leprosa & Tilia sp. & Switzerland & CBS 276.87 & AJ302463 & - \\
\hline Eutypella microtheca & Ulmus procera & South Australia & ADEL300 & HQ692560 & HQ692528 \\
\hline Eutypella microtheca & Citrus paradisi & New South Wales, Australia & HVGRF02 & HQ692569 & HQ692533 \\
\hline Eutypella microtheca & Vitis vinifera & New South Wales, Australia & $\mathrm{T} 2 \mathrm{R} 2 \mathrm{~S} 7$ & HQ692566 & HQ692532 \\
\hline Eutypella microtheca & Vitis vinifera & Worcester, WC, South Africa & STEU 8107 & KY111629 & KY111608 \\
\hline Eutypella microtheca & Vitis vinifera & Robertson, WC, South Africa & STEU 8108 & KY111630 & KY111609 \\
\hline Eutypella microtheca & Vitis vinifera & Stellenbosch, WC, South Africa & STEU 8109 & KY111631 & KY111610 \\
\hline Eutypella microtheca & Vitis vinifera & Worcester, WC, South Africa & STEU 8110 & KY111632 & KY111611 \\
\hline Eutypella microtheca & Vitis vinifera & Calitzdorp, WC, South Africa & STEU 8111 & KY111633 & KY111612 \\
\hline Eutypella quartenata & Fagus sulvatica & Switzerland & CBS 278.87 & AJ302469 & - \\
\hline Eutypella vitis & Vitis labrusca & Illinois, U.S.A. & ATCC64171 & AJ302466 & - \\
\hline Eutypella vitis & Vitis vinifera & Michigan, U.S.A. & MSUELM13 & DQ006943 & DQ006999 \\
\hline Peroneutypa alsophila & Arthrocnemum fruticosum & France & CBS 250.87 & AJ302467 & - \\
\hline Peroneutypa kochiana & Atriplex halimus & Almeria, Spain & $\mathrm{F}-092,373$ & AJ302462 & - \\
\hline Peroneutypa scoparia & Robinia pseudoacacia & France & CBS 242.87 & AJ302465 & - \\
\hline Peroneutypa scoparia & Robinia pseudoacacia & France & DFMAL100 & GQ293962 & GQ294029 \\
\hline
\end{tabular}


Etymology. Named after the colony color, which is mostly cream. Type. South Africa, Western Cape Province, Durbanville, Hooggelegen, on dead wood of V. vinifera, 11 August 2014, P. Moyo, holotype PREM 61675, culture ex-type CBS $142718=$ STEU 8082. Stromata on wood or bark, poorly developed, with a charcoal-like appearance. Perithecia scattered or in rows (Fig. 4A), circular to ovoid, (228-) 232 to $376(-395) \mu \mathrm{m}$ diam. Ostioles apparent on surface of substrate, emerging on surface separately, 3 to 4 sulcate. Asci clavate, with apical ring, octosporous, long stipitate, (23-) 26 to 58.5 (-62) $\times 5$ to $7.5 \mu \mathrm{m}$. Ascospores yellowish, allantoid, (5.5-) 6 to $8 \times 1$ to $2 \mu \mathrm{m}$. Colonies on PDA-C are cream and flat, sometimes with white aerial mycelium. Conidia hyaline, filiform, (19-) 22 to $33 \times 1$ to $1.5 \mu \mathrm{m}$.

Other material examined. South Africa, Western Cape Province, Darling, on dead wood of $V$. vinifera, 11 November 2013, P. Moyo, culture number STEU 8101 (PREM 61676); Darling, on dead wood of V. vinifera, 12 June 2012, F. Halleen, culture number STEU 8084. Algeria, on Fraxinus sp., Sphaeria leptoplaca PC MC8636; on Arundo mauritanica, S. leptoplaca PC MC8635; on A. mauritanica, S. consobrina PC MC5627; on A. mauritanica, S. consobrina PC MC5626.

Notes. Variation in cultural growth of individual isolates of this species was observed. For example, an isolate could be cream and very flat with no aerial mycelium on one PDA-C plate and be cream with white aerial mycelium on another plate, despite being plated at the same time and exposed to same incubation conditions.

E. cremea is similar to E. leptoplaca and E. tetragona (E. tetragona as described by Rappaz 1987) in having 3 to 4 sulcate ostioles emerging separately, yellowish ascospores, and spherical to ovoid perithecia, but these species differ in the length of the spore bearing part of their asci. E. cremea has a higher maximum length of their spore bearing part ([23-] 26 to $58.5[-62] \mu \mathrm{m})$ compared with E. leptoplaca $(25$ to $40 \mu \mathrm{m})$ and E. tetragona (30 to $45[-55] \mu \mathrm{m})$ (Rappaz 1987). Additionally, E. tetragona has larger perithecia (300 to 400 [-500] $\mu \mathrm{m}$ diam.) versus E. leptoplaca (150 to $300 \mu \mathrm{m}$ diam.) (Rappaz 1987) and E. cremea (228-) 232 to $376(-395) \mu \mathrm{m}$ diam.).

Eutypa lata (Pers.) Tul. \& C. Tul., Selecta Fungorum Carpologia: Xylariei- Valsei- Spaeriei 2:56, 1863 (Fig. 5). Stromata on bark and wood. Perithecia oval, (307-) 334 to 497 (-553) $\mu \mathrm{m}$ diam. Ostioles not sulcate. Asci spindle shaped, 8 -spored, long stipitate, truncate at apex, (26-) 32 to $69(-83) \times 6$ to $7(-8) \mu \mathrm{m}$. Ascospores allantoid, 7 to $10(-13) \times 1$ to $2 \mu \mathrm{m}$. Colonies cottony white on PDA-C, but later turn gray to black and underside of colonies is cream. Conidia single celled, filiform, (13-) 27 to 43 (-49) $\times 1$ to $2 \mu \mathrm{m}$.

Material examined. South Africa, Western Cape Province, Durbanville, Hooggelegen, on dead wood of V. vinifera, 20 June 2013, P. Moyo, culture number STEU 8218.

Eutypella citricola Speg., Anales del Museo Nacional de Buenos Aires 6: 245, 1898 (Fig. 6). Stromata on wood or bark, in pustules unevenly distributed or grouped. Perithecia spherical to ovoid, (280-) 306 to 585 (-603) $\mu \mathrm{m}$ diam., surrounded by white powdery layer. Ostioles apparent on surface, emerging singly or in groups, sulcate. Asci octosporous, clavate, long-stiped, (34-) 36 to $61(-73) \times(5-) 5.5$ to 8 $(-9) \mu \mathrm{m}$. Ascospores pale yellow, allantoid, (7-) 8 to $10(-12) \times 2$ to $3 \mu \mathrm{m}$. Colonies on PDA-C white but turning black with age starting from the center of colony, black color more apparent from beneath the colony. Conidia filiform, (13-) 14 to $19(-20) \times 1$ to $2 \mu \mathrm{m}$.

Material examined. South Africa, Western Cape Province, Durbanville, Diemersdal, on dead wood of V. vinifera, 18 November 2013, P. Moyo, culture number STEU 8231.

Eutypella microtheca Trouillas, W. M. Pitt \& Gubler, Fungal Diversity 49: 217, 2011 (Fig. 7). Stromata on wood and bark, pustular and breaking through the periderm of the host. Perithecia circular to ovoid, surrounded by a white powdery layer, (273-) 307 to 655 $(-656) \mu \mathrm{m}$ diam. Ostioles sulcate, emerging in groups through the cracked periderm. Asci long stipitate, clavate, octosporous, (33-) 35 to $65(-94) \times 6$ to $9 \mu \mathrm{m}$. Ascospores pale yellow, allantoid to suballantoid, (6-) 7 to $11(-12) \times 2$ to $3 \mu \mathrm{m}$. Colonies start as white turning pink in color with age. Conidia were not observed.

Material examined. South Africa, Western Cape Province, Calitzdorp, on dead wood of $V$. vinifera, 1 November 2014, P. Moyo, culture number STEU 8111.

Notes. A higher maximum length of the spore bearing part of asci $(94 \mu \mathrm{m})$ and a higher ascospore length $(12 \mu \mathrm{m})$ are reported here compared with 60 and $11 \mu \mathrm{m}$, respectively, reported by Trouillas et al. (2011).

Occurrence of sexual morphs in vineyards. The survey of fruiting structures in vineyards revealed five species to produce fruiting
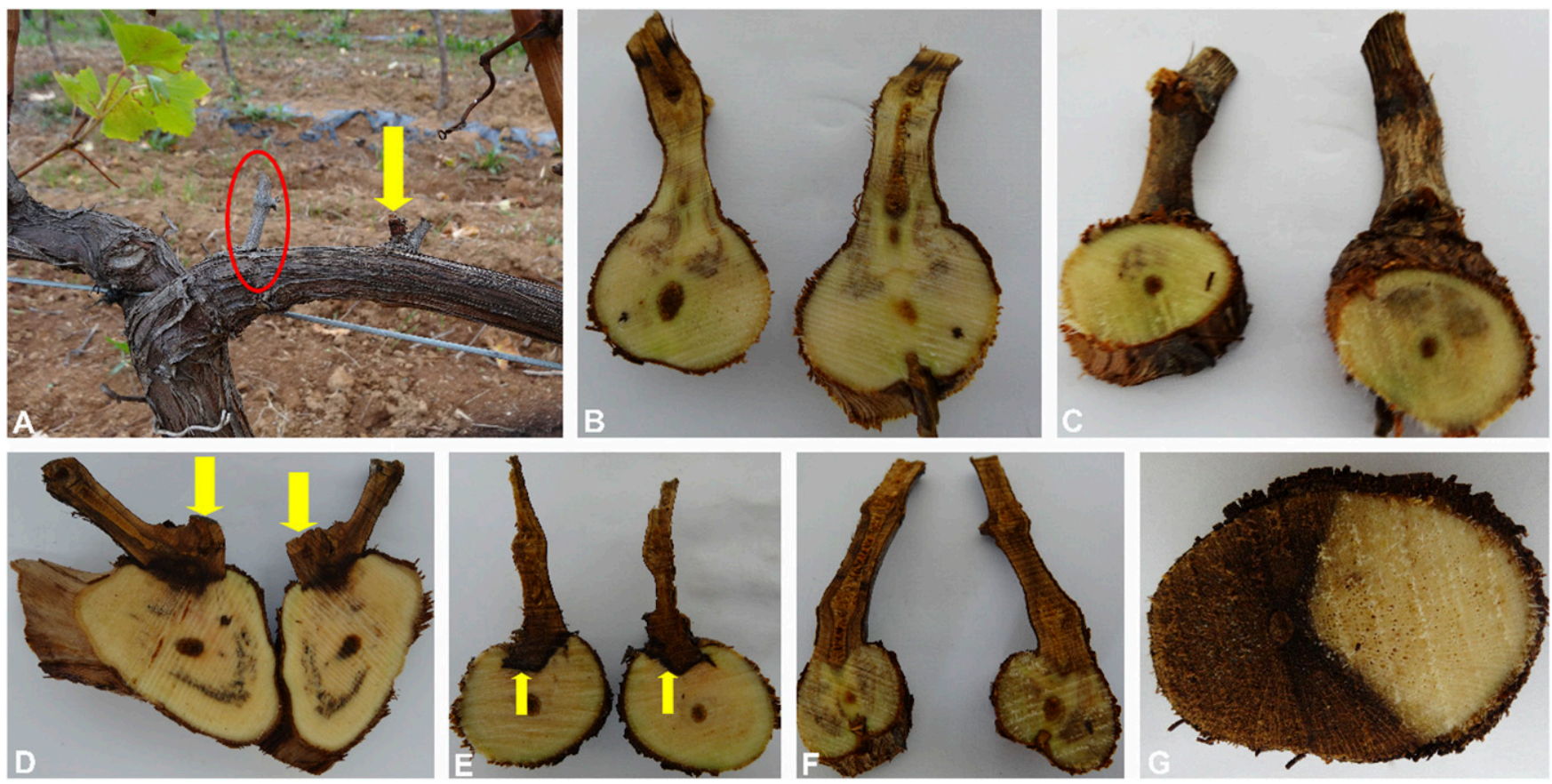

Fig. 1. Disease symptoms observed on dying spurs and cordons/trunks of naturally infected grapevines in Western Cape Province of South Africa. A, Four-year-old grapevine showing a dying spur (circled in red) and poor bud burst (showed by yellow arrow) in the field. B, Brown streaks extending from a pruning wound of a dying spur. C, Brown sectorial necrosis seen from the reverse side of the dying spur presented in B. D, Brown/black streaks extending from a dying spur which has a wound (yellow arrow) next to it. E, Black line (yellow arrow) at the border of dead and live tissue. F, Brown streaks in a dying spur. G, Wedge-shaped necrosis. 
bodies on dead grapevine wood. Fruiting bodies of E. lata were found on $51 \%$ of the grapevine wood samples collected. Perithecia of $C$. ampelina were found on $38 \%$ of the wood pieces, whereas perithecia of E. cremea, E. citricola, and E. microtheca were found on 6, 4 , and $1 \%$ of the wood pieces, respectively.

Diatrypaceae species and symptom associations. The dying spurs presented a higher diversity of Diatrypaceae than the wedgeshaped cankers on grapevines. From a total of 360 dying spurs processed, seven species, namely $C$. ampelina, $C$. rabenhorstii, $E$. cremea, E. consobrina, E. lata, E. citricola, and E. microtheca were isolated from the two grapevine cultivars sampled from the five different areas within Western Cape Province of South Africa. C. ampelina was the most frequently isolated species $(46.4 \%$ of the total number of Diatrypaceae isolates) followed by E. citricola (26.8\%), E. lata $(20.1 \%)$, E. cremea (4.3\%), E. microtheca (1.2\%), E. consobrina $(0.6 \%)$, and $C$. rabenhorstii $(0.6 \%)$. Isolations from wedgeshaped necrosis collected from 10 cultivars in eight locations in the Western Cape yielded four species, namely C. ampelina, E. lata, E. cremea, and E. citricola. E. lata represented the most frequent species detected in the wedge-shaped necrosis $(89.2 \%$ of all Diatrypaceae

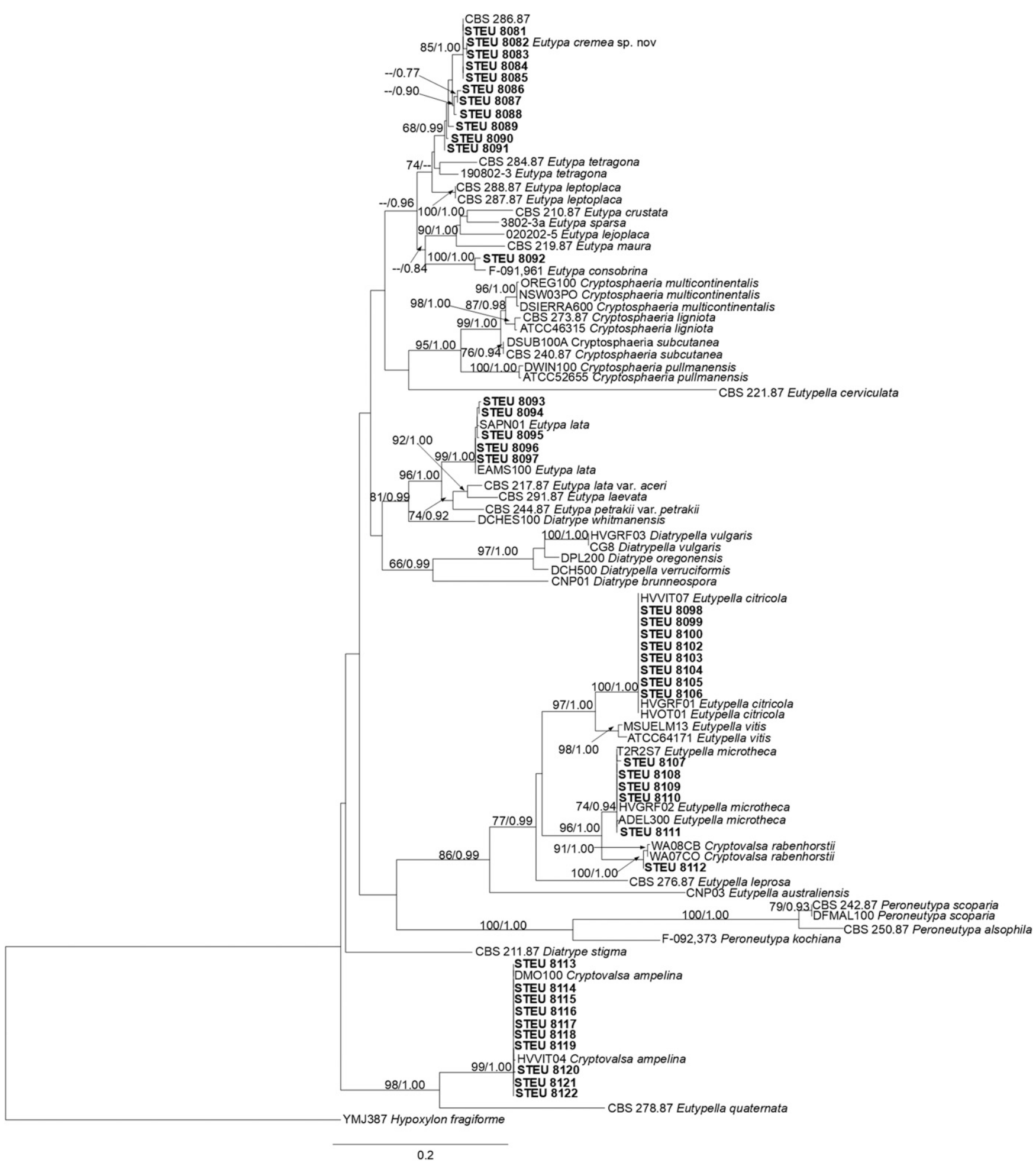

Fig. 2. Maximum likelihood tree derived from the combined analysis of ITS and $\beta$-tubulin sequence data. Maximum likelihood bootstrap support values and Bayesian posterior probability scores are given at the nodes. Hypoxylon fragiforme served as an outgroup. Isolates obtained from this study are in bold. 
isolates obtained), followed by E. citricola (8.5\%), E. cremea (1.4\%), and $C$. ampelina $(0.9 \%)$. The wedge-shaped cankers from which $E$. citricola and $E$. cremea were isolated were often associated with dieback symptoms, and not strictly from grapevine expressing Eutypa dieback symptoms. In both symptom types (dying spurs and wedge-shaped necrosis), a number of samples were infected by more than one species. More than one fungal species was isolated from a single symptom in 17 and $4 \%$ of the samples from dying spurs and wedge-shaped necrosis, respectively, which yielded Diatrypaceae species. C. ampelina and E. lata were found in 83 and $100 \%$ of the samples from dying spurs and wedge-shaped necrosis, respectively, which yielded more than one fungal species (Table 2).

\section{Discussion}

There has been an increase in the number of studies of the Diatrypaceae occurring on grapevine recently, and the use of DNA sequences makes it easier to identify taxa to generic and species level. In this study, phylogenetic analyses allowed the identification of seven Diatrypaceae species from declining grapevines in South Africa, namely C. ampelina, C. rabenhorstii, E. lata, E. consobrina, E. cremea, E. citricola, and E. microtheca. Except for E. lata and C. ampelina, the taxa found in this study are reported for the first time on grapevine in South Africa.

After finding close resemblance of the type materials of E. leptoplaca and E. consobrina, Trouillas and Gubler (2004) concluded that the French isolate CBS 286.87 designated as E. leptoplaca by Rappaz (1987) could be E. consobrina. The close resemblance of the type materials of these two species was confirmed in this study. However, the phylogenetic results of this study strongly support the separation of this isolate, which clustered with some of the Eutypa strains collected in the present study, from isolates of both E. leptoplaca and E. consobrina. This cluster is described as a new species and as a result, strain CBS 286.87 was reidentified as E. cremea in this study. E. cremea could be distinguished from $E$. consobrina based on both phylogenetic analyses and morphological characteristics. Colonies of E. cremea are cream on PDA-C while those of E. consobrina were apricot (data not shown). Furthermore, perithecia of E. consobrina collected from nongrapevine material (data unpublished) were larger ([249-] 262 to 451 $[-468] \mu \mathrm{m}$ diam.) and also form larger asci ([25-] 27 to $69[-82] \times 5$ to $7 \mu \mathrm{m})$ and ascospores (6 to $10[-11] \times[1-] 1.5$ to $3 \mu \mathrm{m})$ than E. cremea.

The newly described species, E. cremea, was isolated from grapevine samples collected from different areas in Western Cape Province including Bonnievale, Constantia, Darling, Durbanville, Hermanus, Robertson, Slanghoek, and Stellenbosch. This shows that this species occurs in a wide geographical area in Western Cape Province of South Africa and therefore, grapevine appears to be a good host for E. cremea. Furthermore, besides its isolation from grapevine, E. cremea has been associated with Arundo donax from Algeria (Rappaz 1987), which indicates its capability to infect multiple hosts.

The identity of Diatrypaceae species associated with wedge-shaped necrosis and spur dieback on grapevine were investigated and results showed that the frequency of isolation of these species from the two symptom types differed considerably. Wedge-shaped cankers on grapevine
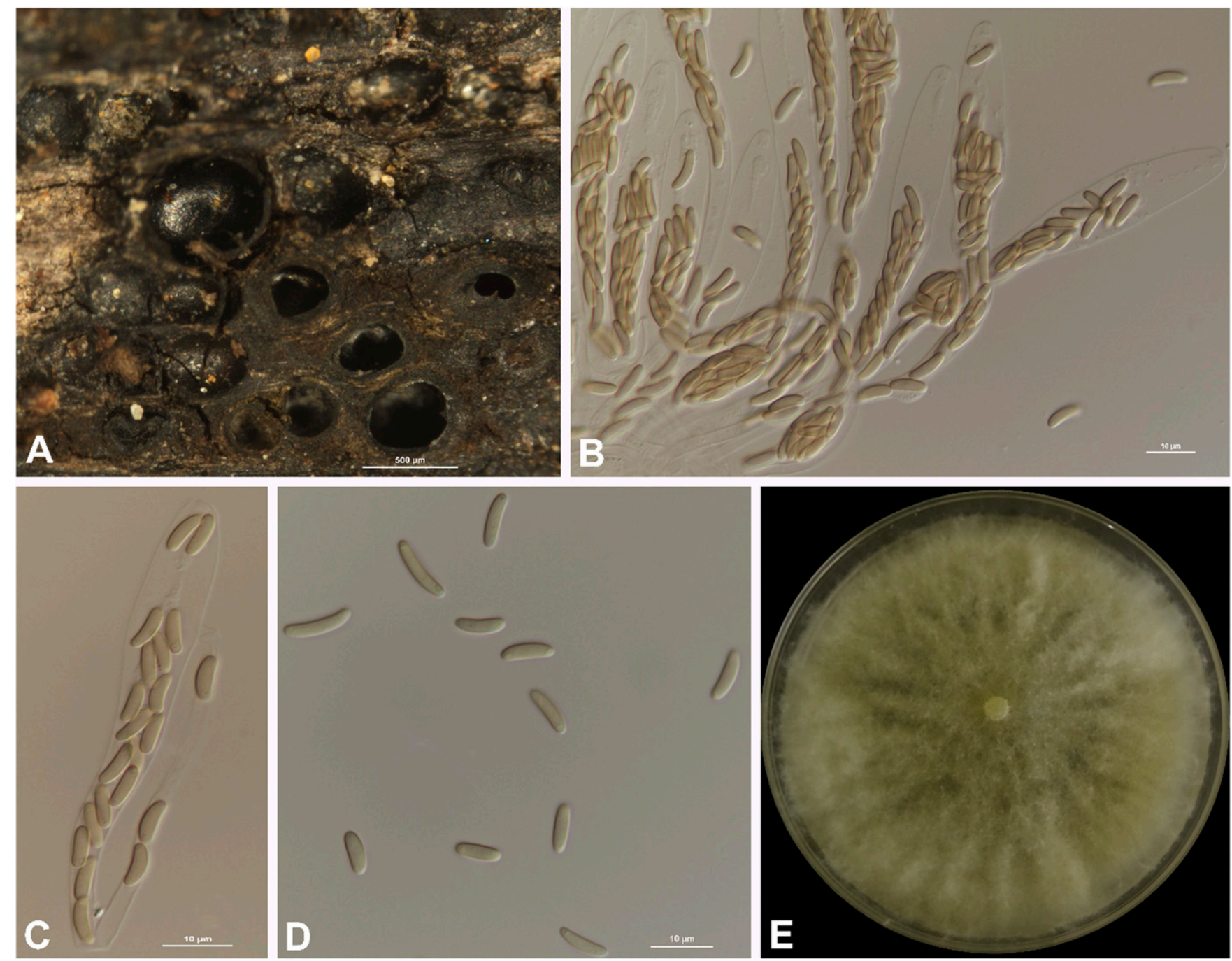

Fig. 3. Morphology of Cryptovalsa ampelina. A, Stromata showing perithecia cavities. B, Group of polysporous asci. C, Clavate, polysporous ascus. D, Allantoid to suballantoid ascospores. $\mathrm{E}$, Colony on PDA-C after 15 days growing at $24^{\circ} \mathrm{C}$ under intermittent light (12 h). 
have, in the past, been associated with E. lata (Moller and Kasimatis 1978), and indeed, this species was found to be the dominant species in this symptom type in the current study. The high incidence of isolation of this pathogen indicates that the wedge-shaped necrosis in grapevine wood could be mostly attributed to E. lata and that this species is an important grapevine canker pathogen in South Africa. E. lata produces toxins (Tey-Rulh et al. 1991) and wood degrading enzymes (English and Davis 1978; Schmidt et al. 1999), which have been implicated in the decline of grapevine. The presence of additional Diatrypaceae species in the same tissue with E. lata further compromises the immunity of the vine and possibly enhance the decline of the infected grapevine.

Isolations from dying Sauvignon blanc and Cabernet Sauvignon spurs resulted in seven species of Diatrypaceae being identified, with C. ampelina being the most frequently isolated species. C. ampelina co-occurred with all the other six species found to infect spurs. However, the frequency in which this species co-occurred with other species was lower than that, in which it occurred alone in both cultivars. The high frequency with which $C$. ampelina was isolated agrees with results of Luque et al. (2014), who found this species to be the most abundant species of the Diatrypaceae in naturally infected grapevine spurs in Spain.
E. lata infects grapevines by means of ascospores, which germinate and colonize the vascular tissue of the trunks and cordons (Moller and Kasimatis 1978, 1980). Mycelium of this fungus is usually not detected in annual canes or the foliage of infected grapevines (Rudelle et al. 2005) and the development of foliar symptoms in Eutypa diebackaffected grapevines has been credited to the phytotoxins produced by E. lata inside the wood (Tey-Rulh et al. 1991). While the dieback of spurs and the low isolation frequency of E. lata could be explained by the translocation of toxins of this fungus from mature wood to the spurs, the higher incidence of isolation of $C$. ampelina in both cultivars in our study could be explained by the capability of $C$. ampelina to better colonize young wood of spurs compared with $E$. lata. This also makes $C$. ampelina an important causal agent of spur dieback in the Western Cape of South Africa. The isolation of several species of Diatrypaceae in vineyards as young as 4 years old, however, could also suggest that these species are involved in the long process of the development of dieback of grapevines, or they may work synergistically with $E$. lata in symptom development.

A higher number of isolates and diversity of Diatrypaceae species were found in Cabernet Sauvignon compared with Sauvignon blanc vineyards. It would seem that Cabernet Sauvignon is more susceptible
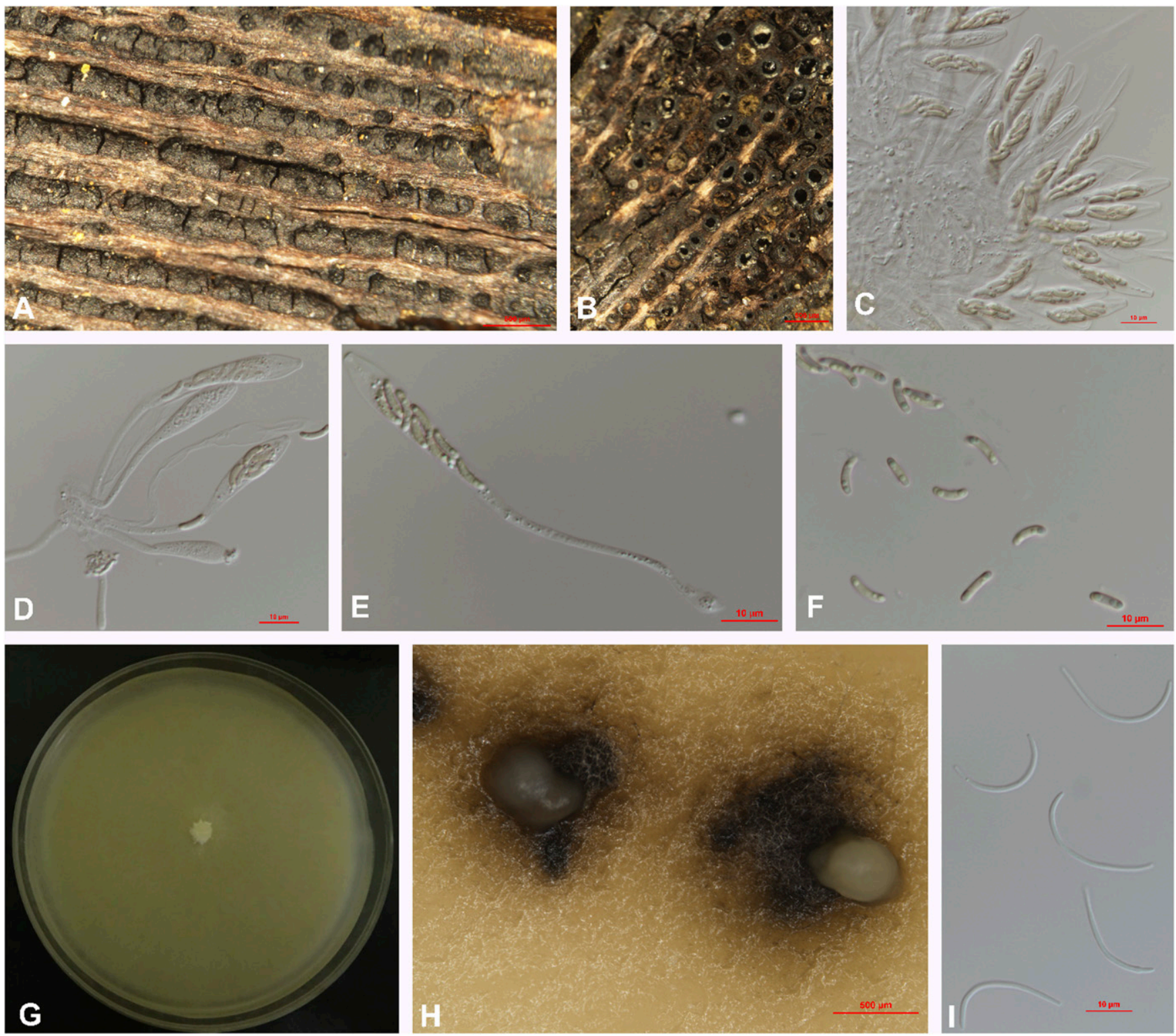

Fig. 4. Morphology of Eutypa cremea from grapevine. A, Stromata showing perithecia in rows. B, Perithecial cavities. C, Asci attached to the hymenium. D, Mature and immature asci. E, Long stalked octosporous ascus. F, Allantoid ascospores. G, Colony on a $90 \mathrm{~mm}$ diam. PDA-C dish after 15 days incubation at $24^{\circ} \mathrm{C}$ under $12 \mathrm{~h}$ of intermittent lighting. H, Spore mass oozing from pycnidia after 30 days of incubation at $24^{\circ} \mathrm{C}$. I, Filiform conidia. 

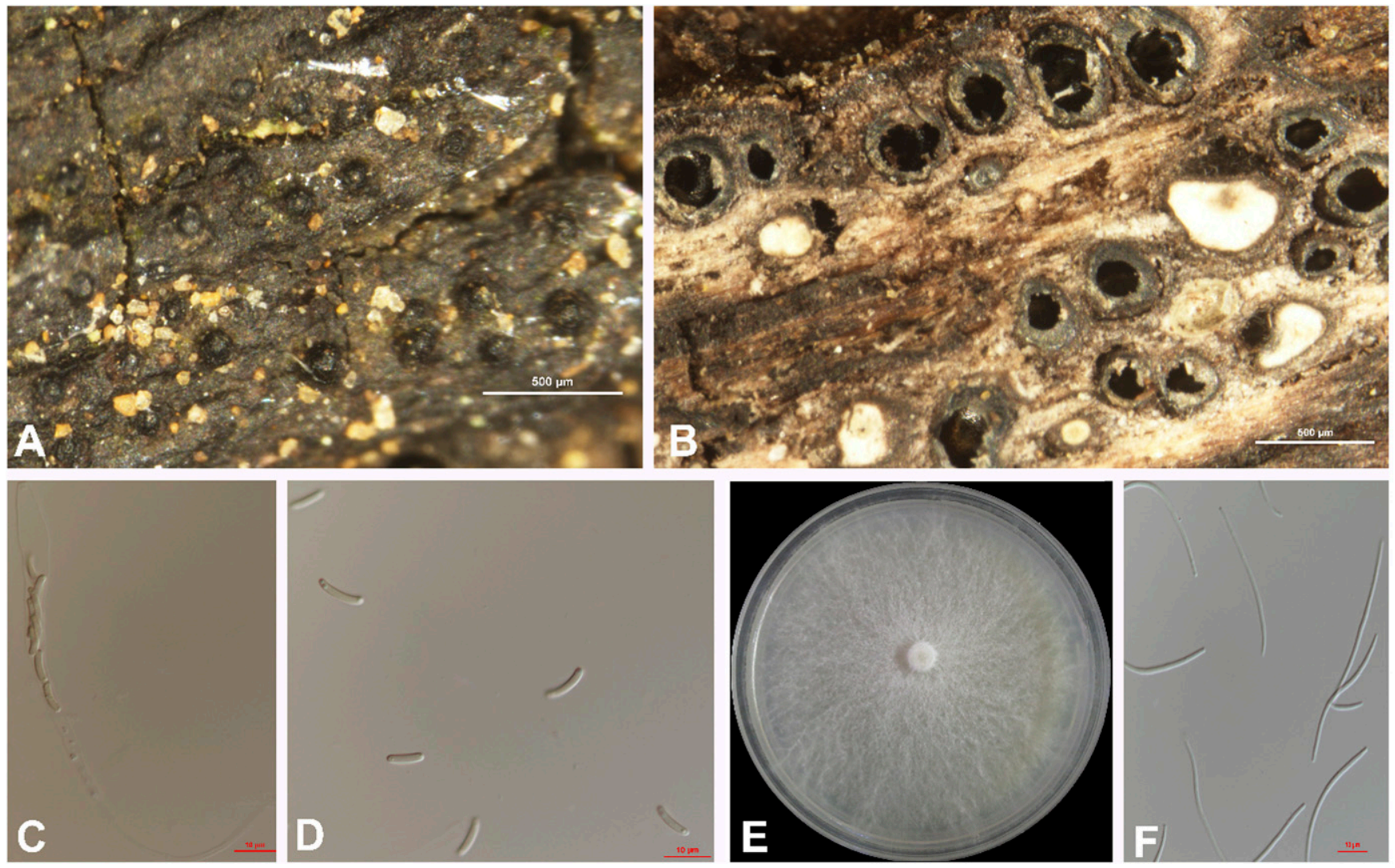

Fig. 5. Morphology of Eutypa lata. A, Stromata on wood. B, Cross-section of stromata. C, Octosporous ascus. D, Allantoid ascospores. E, Colony on PDA-C after 15 days growing at $24^{\circ} \mathrm{C}$ under intermittent light $(12 \mathrm{~h})$. F, Filiform conidia.
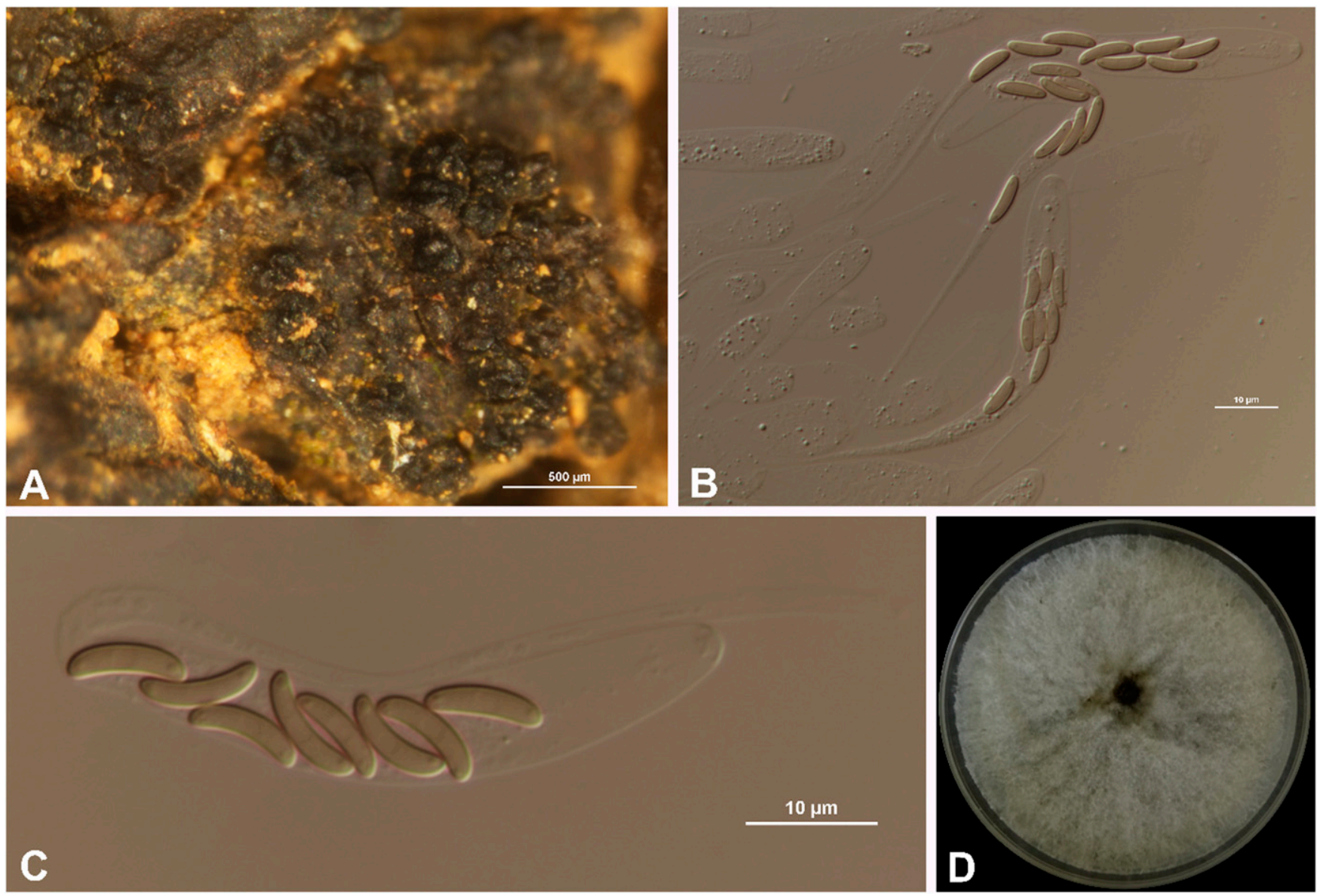

Fig. 6. Morphology of Eutypella citricola. A, Stromata. B, Group of asci. C, Long-stiped, octosporous ascus. D, Colony after 15 days on PDA-C dish (90 mm diam.) incubated at $24^{\circ} \mathrm{C}$ under intermittent light $(12 \mathrm{~h})$. 
to these fungi than Sauvignon blanc. Péros and Berger (1994) reported that Cabernet Sauvignon has higher susceptibility to E. lata than Sauvignon blanc and this could be the case for the other Diatrypaceae species as well. Apart from species that were isolated fairly frequently from spurs, $C$. rabenhorstii and E. consobrina were each isolated only once, which suggests that their presence in grapevine wood might be influenced by certain conditions, such as the occurrence of other woody hosts in the vicinity of vineyards. This assumption is supported by other studies, which found diatrypaceous species occurring on grapevine to also occur in other woody hosts surrounding vineyards and postulated that these hosts act as inoculum sources to vineyards (Trouillas et al. 2010, 2011). Furthermore, the low frequency of isolation of these species in the present study makes it difficult to establish their role in grapevine decline.

While E. lata has been known to be the most important diatrypaceous pathogen in many grapevine-producing areas of the world, C. ampelina, E. microtheca, and E. citricola also seem to be geographically widespread, having been reported in areas including Australia (Trouillas et al. 2011), California (Trouillas et al. 2010), Chile (Díaz et al. 2011), Mexico (Paolinelli-Alfonso et al. 2015), and northeast Spain (Luque et al. 2012). Before this study, C. rabenhorstii has only been reported on grapevine in Australia (Trouillas et al. 2011). Results from the current study also extend the host range of E. consobrina from Arundo mauritanica to Vitis spp. and further increase the number of Diatrypaceae species found to colonize grapevine wood.

Extensive searches for perithecia in vineyards revealed that five Diatrypaceae species have the ability to complete their life cycle on grapevine tissue. However, perithecia of species such as E. microtheca, E. citricola, and E. cremea were not as prevalent in Western Cape vineyards as those of $C$. ampelina and E. lata. Nevertheless, finding stromata of these species on dead grapevine wood suggests that they may be involved in dieback and eventually death of grapevines. The epidemiology and biology of the newly discovered Diatrypaceae species on grapevine is currently unknown. However, the isolation of these species from necrotic tissues below pruning wounds of naturally infected spurs and from wedge-shaped cankers associated with dieback symptoms, in this study, suggests that these species, similar to E. lata, infect grapevine via pruning wounds on spurs and cordons and develop inside vascular tissues.
Prevention of the introduction of causal pathogens into the vineyard is the most reliable control strategy against canker diseases. Prevention of infection is achieved by strategies that include the use of pruning wound protectants (Ayres et al. 2017; Sosnowski et al. 2008), avoiding pruning immediately after rainfall (Petzoldt et al. 1983), and sanitation.

Table 2. The diversity of Diatrypaceae fungi isolated from dying spurs of Cabernet Sauvignon (CS) and Sauvignon blanc (SB) vineyards as well as wedge-shaped necrosis on wood pieces collected from different vineyards in Western Cape Province of South Africa

\begin{tabular}{|c|c|c|c|}
\hline \multirow[b]{3}{*}{ Species isolated } & \multicolumn{3}{|c|}{ Number of samples } \\
\hline & \multicolumn{2}{|c|}{$\begin{array}{l}\text { Dying } \\
\text { spurs } \\
\end{array}$} & \multirow{2}{*}{$\begin{array}{l}\text { Wedge-shapec } \\
\text { necrosis }^{\mathrm{a}}\end{array}$} \\
\hline & SB & $\mathbf{C S}$ & \\
\hline Cryptovalsa ampelina & 27 & 29 & 1 \\
\hline Eutypa lata & 17 & 7 & 181 \\
\hline Eutypa cremea & 3 & 1 & 2 \\
\hline Eutypella citricola & 13 & 17 & 11 \\
\hline Eutypella microtheca & - & 1 & - \\
\hline $\begin{array}{l}\text { Cryptovalsa ampelina }+ \text { Cryptovalsa } \\
\text { rabenhorstii }\end{array}$ & - & 1 & - \\
\hline Cryptovalsa ampelina + Eutypa lata & 5 & - & 1 \\
\hline $\begin{array}{l}\text { Cryptovalsa ampelina }+ \text { Eutypa } \\
\text { consobrina }\end{array}$ & 1 & - & - \\
\hline Cryptovalsa ampelina + Eutypa cremea & - & 2 & - \\
\hline $\begin{array}{l}\text { Cryptovalsa ampelina }+ \text { Eutypella } \\
\text { citricola }\end{array}$ & 2 & 7 & - \\
\hline $\begin{array}{l}\text { Cryptovalsa ampelina }+ \text { Eutypella } \\
\text { microtheca }\end{array}$ & - & 1 & - \\
\hline $\begin{array}{l}\text { Cryptovalsa ampelina }+ \text { Eutypa lata }+ \\
\text { Eutypella citricola }\end{array}$ & - & 1 & - \\
\hline Eutypa lata + Eutypa cremea & - & - & 1 \\
\hline Eutypa lata + Eutypella citricola & - & 3 & 7 \\
\hline Eutypa cremea + Eutypella citricola & - & 1 & - \\
\hline $\begin{array}{l}\text { Total number of samples yielding } \\
\text { Diatrypaceae isolates }\end{array}$ & 68 & 71 & 204 \\
\hline Total number of samples collected & 190 & 170 & 296 \\
\hline
\end{tabular}

${ }^{a}$ This symptom type was collected from wood of 10 different grapevine cultivars.

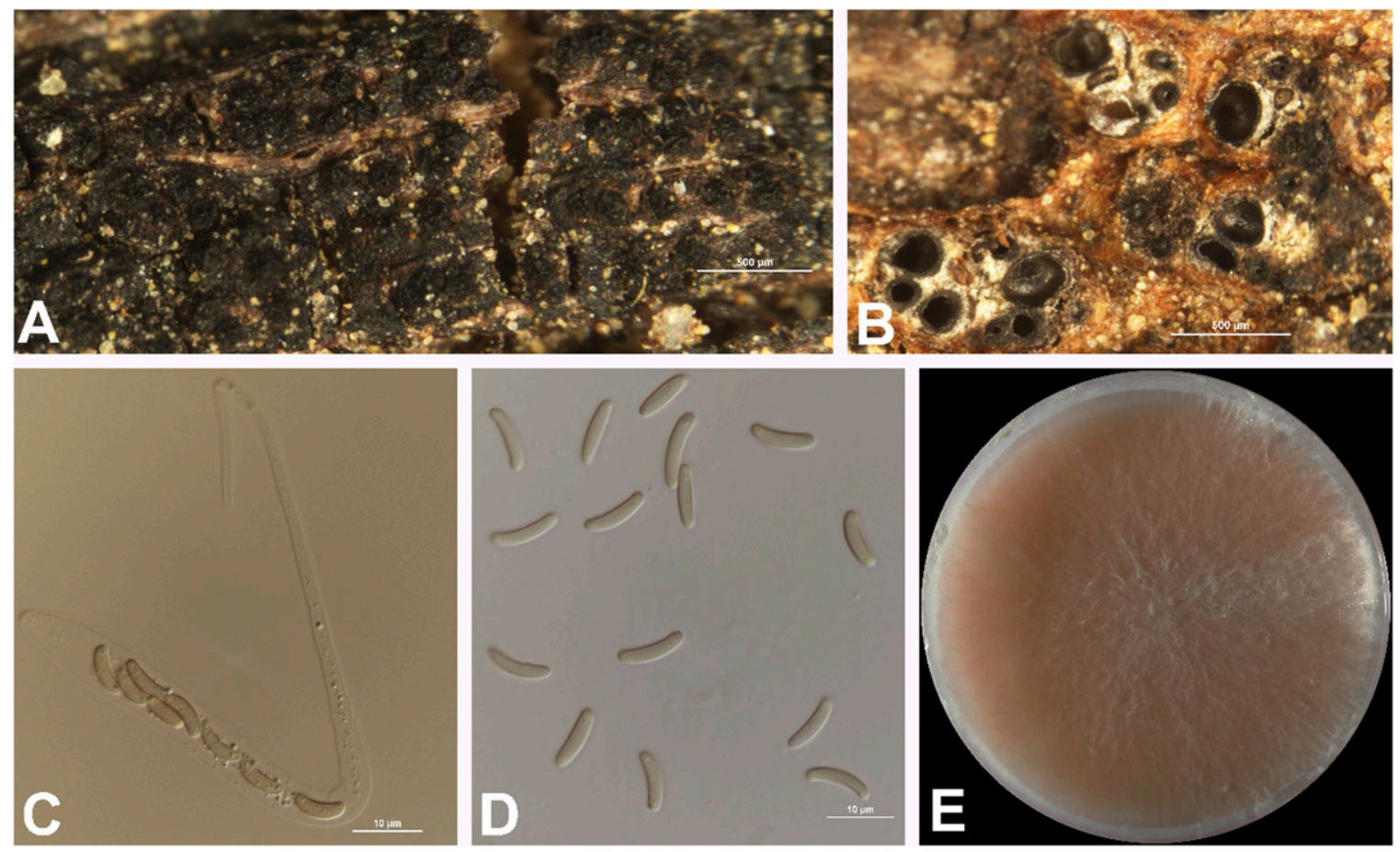

Fig. 7. Morphology of Eutypella microtheca. A, Stromata with sulcate ostioles protruding on the surface. B, Stromata with a white, powdery layer surrounding the perithecial. C, Octosporous ascus. D, Allantoid ascospores. E, Colony after 15 days on $90 \mathrm{~mm}$ diam. PDA-C dish incubated at $24^{\circ} \mathrm{C}$ under intermittent light (12 h). 
An in vitro study by Gramaje et al. (2012) showed that fungicides such as fluazinum, carbendazim, and tebuconazole were effective against mycelial growth of species including $C$. ampelina, E. citricola, and E. microtheca. However, no other prevention strategies have so far been evaluated for the potential to control or prevent infection of grapevine caused by the Diatrypaceae species, including those detected in this study, except for fungicides known to reduce E. lata infection. Further research on management strategies against canker diseases, poor budburst, and spur dieback of grapevine need to include all Diatrypaceae species involved in the respective disease complexes.

\section{Acknowledgments}

The authors wish to acknowledge funding received from the Agricultural Research Council (ARC), National Research Foundation (NRF), Technology and Human Resources for Industry Programme (THRIP), and Department of Plant Pathology, University of Stellenbosch. We gratefully acknowledge the herbarium curators of the Museum National d'Histoire Naturelle, Paris (PC), for providing herbarium specimens. We also greatly appreciate assistance from the ARC-Infruitec-Nietvoorbij technical team.

\section{Literature Cited}

Alfaro, M. E., Zoller, S., and Lutzoni, F. 2003. Bayes or bootstrap? A simulation study comparing the performance of Bayesian Markov chain Monte Carlo sampling and bootstrapping in assessing phylogenetic confidence. Mol. Biol. Evol. 20:255-266.

Ayres, M. R., Wicks, T. J., Scott, E. S., and Sosnowski, M. R. 2017. Developing pruning wound protection strategies for managing Eutypa dieback. Aust. J. Grape Wine Res. 23:103-111.

Carter, M. V. 1988. Eutypa dieback. Pages 32-34 in: Compendium of Grape Diseases. R. Pearson and A. Goheen, eds. APS Press, St Paul, MN.

Castresana, J. 2000. Selection of conserved blocks from multiple alignments for their use in phylogenetic analysis. Mol. Biol. Evol. 17:540-552.

Catal, M., Jordan, S. A., Butterworth, S. C., and Schilder, A. M. C. 2007. Detection of Eutypa lata and Eutypella vitis in grapevine by nested multiplex polymerase chain reaction. Phytopathology 97:737-747.

Damm, U., Mostert, L., Crous, P. W., and Fourie, P. H. 2008. Novel Phaeoacremonium species associated with necrotic wood of Prunus trees. Persoonia 20:87-102.

Díaz, G. A., Prehn, D., and Latorre, B. A. 2011. First Report of Cryptovalsa ampelina and Eutypella leprosa associated with grapevine trunk diseases in Chile. Plant Dis. 95:490.

English, H., and Davis, J. R. 1978. Eutypa armeniacae in apricot: Pathogenesis and induction of xylem soft-rot. Hilgardia 46:193-204.

Ferreira, J. H. S. 1987. Dieback of grapevines in South Africa. PhD Thesis, University of the Western Cape, South Africa.

Glass, N. L., and Donaldson, G. C. 1995. Development of primer sets designed for use with the PCR to amplify conserved genes from filamentous ascomycetes. Appl. Environ. Microbiol. 61:1323-1330.

Glawe, D. A., and Rogers, J. D. 1984. Diatrypaceae in the Pacific Northwest. Mycotaxon 20:401-460.

Gramaje, D., Ayres, M. R., Trouillas, F. P., and Sosnowski, M. R. 2012. Efficacy of fungicides on mycelial growth of diatrypaceous fungi associated with grapevine trunk disease. Australas. Plant Pathol. 41:295-300.

Guindon, S., and Gascuel, O. 2003. A simple, fast, and accurate algorithm to estimate large phylogenies by maximum likelihood. Syst. Biol. 52:696-704.

Hillis, D. M., and Bull, J. J. 1993. An empirical test of bootstrapping as a method for assessing confidence in phylogenetic analysis. Syst. Biol. 42:182-192.

Huelsenbeck, J. P., and Ronquist, F. 2001. MRBAYES: Bayesian inference of phylogeny. Bioinformatics 17:754-755.

Jordan, S., and Schilder, A. 2005. Eutypella vitis, a potential pathogen of grapevines in Michigan. Phytopathology 95:S51 (Abstract).

Katoh, K., Misawa, K., Kuma, K., and Miyata, T. 2002. MAFFT: a novel method for rapid multiple sequence alignment based on fast Fourier transform. Nucleic Acids Res. 30:3059-3066.

Kearse, M., Moir, R., Wilson, A., Stones-Havas, S., Cheung, M., Sturrock, S., Buxton, S., Cooper, A., Markowitz, S., Duran, C., Thierer, T., Ashton, B., Mentjies, P., and Drummond, A. 2012. Geneious Basic: an integrated and extendable desktop software platform for the organization and analysis of sequence data. Bioinformatics 28:1647-1649.

Luque, J., Elena, G., Garcia-figueres, F., Reyes, J., Barrios, G., and Legorburu, F. J. 2014. Natural infections of pruning wounds by fungal trunk pathogens in mature grapevines in Catalonia (Northeast Spain). Aust. J. Grape Wine Res. 20:134-143.
Luque, J., Garcia-figueres, F., Legorburu, F. J., Muruamendiaraz, A., Armengol, J., and Trouillas, F. P. 2012. Species of Diatrypaceae associated with grapevine trunk diseases in Eastern Spain. Phytopathol. Mediterr. 51:528-540.

Luque, J., Sierra, D., Torres, E., and Garcia, F. 2006. Cryptovalsa ampelina on grapevines in N.E. Spain: identification and pathogenicity. Phytopathol. Mediterr. 45:S101-S109.

Moller, W. J., and Carter, M. V. 1965. Production and dispersal of ascospores in Eutypa armeniacae. Aust. J. Biol. Sci. 18:67-80.

Moller, W. J., and Kasimatis, A. N. 1978. Dieback of grapevines caused by Eutypa armeniacae. Plant Dis. Rep. 62:254-258.

Moller, W. J., and Kasimatis, A. N. 1980. Protection of grapevine pruning wounds from Eutypa dieback. Plant Dis. 64:278-280.

Mostert, L., Halleen, F., Creaser, M. L., and Crous, P. W. 2004. Cryptovalsa ampelina, a forgotten shoot and cane pathogen of grapevines. Australas. Plant Pathol. 33:295-299.

Moyo, P., Mostert, L., Bester, M., and Halleen, F. 2016. Trunk disease fungi associated with Diospyros kaki in South Africa. Plant Dis. 100:2383-2393.

Paolinelli-Alfonso, M., Serrano-Gomez, C., and Hernandez-Martinez, R. 2015 Occurrence of Eutypella microtheca in grapevine cankers in Mexico. Phytopathol. Mediterr. 54:86-93.

Péros, J. P., and Berger, G. 1994. A rapid method to assess the aggressiveness of Eutypa lata isolates and the susceptibility of grapevine cultivars to Eutypa dieback. Agronomie 14:515-523.

Petzoldt, C. H., Sall, M. A., and Moller, W. J. 1983. Factors determining the relative number of ascospores released by Eutypa armeniacae in California. Plant Dis. 67:857-860.

Pitt, W. M., Huang, R., Trouillas, F. P., Steel, C. C., and Savocchia, S. 2010. Evidence that Eutypa lata and other diatrypaceous species occur in New South Wales vineyards. Australas. Plant Pathol. 39:97-106.

Pitt, W. M., Trouillas, F. P., Gubler, W. D., Savocchia, S., and Sosnowski, M. R. 2013. Pathogenicity of diatrypaceous fungi on grapevines in Australia. Plant Dis. 97:749-756.

Rappaz, F. 1987. Taxonomie et nomenclature des Diatrypacées à asques octosporées. Mycol. Helv. 2:285-648.

Rolshausen, P. E., Baumgartner, K., Travadon, R., Fujiyoshi, P., Pouzoulet, J., and Wilcox, W. F. 2014. Identification of Eutypa spp. causing Eutypa dieback of grapevine in eastern North America. Plant Dis. 98:483-491.

Rolshausen, P. E., Mahoney, N. E., Molyneux, R. J., and Gubler, W. D. 2006. Reassessment of the species concept in Eutypa lata, the causal agent of Eutypa dieback of grapevine. Phytopathology 96:369-377.

Rudelle, J., Octave, S., Kaid-Harche, M., Roblin, G., and Fleurat-Lessard, P. 2005. Structural modifications induced by Eutypa lata in the xylem of trunk and canes of Vitis vinifera.. Funct. Plant Biol. 32:537-547.

Safodien, S., Halleen, F., Crous, P. W., Smit, W. A., and Botha, A. 2005 Molecular characterisation and identification of Eutypa spp. from grapevines in South Africa. Phytopathol. Mediterr. 44:86-87 (Abstract).

Schilder, A. M. C., Butterworth, S. C., and Catal, M. 2003. Eutypa dieback: progression and detection of the pathogen in grapevines. Phytopathology 93 S76 (Abstract).

Schmidt, C. S., Wolf, G. A., and Lorenz, D. 1999. Production of extracellular hydrolytic enzymes by the grapevine dieback fungus Eutypa lata. J. Plant Dis. Prot. 106:1-11

Sosnowski, M. R., Creaser, M. L., Wicks, T. J., Lardner, R., and Scott, E. S. 2008 Protection of grapevine pruning wounds from infection by Eutypa lata. Aust. J. Grape Wine Res. 14:134-142.

Tey-Rulh, P., Philippe, I., Renaud, J. M., Tsoupras, G., De Angelis, P., Fallot, J., and Tabacchi, R. 1991. Eutypine, a phytotoxin produced by Eutypa lata the causal agent of dying-arm disease of grapevine. Phytochemistry 30:471-473.

Trouillas, F. P., and Gubler, W. D. 2004. Identification and characterization of Eutypa leptoplaca, a new pathogen of grapevine in Northern California Mycol. Res. 108:1195-1204.

Trouillas, F. P., and Gubler, W. D. 2010. Pathogenicity of Diatrypaceae species in grapevines in California. Plant Dis. 94:867-872.

Trouillas, F. P., Pitt, W. M., Sosnowski, M. R., Huang, R. J., Peduto, F., Loschiavo, A., Savocchia, S., Scott, E. S., and Gubler, W. D. 2011. Taxonomy and DNA phylogeny of Diatrypaceae associated with Vitis vinifera and other woody plants in Australia. Fungal Divers. 49:203-223.

Trouillas, F. P., Urbez-Torres, J. R., and Gubler, W. D. 2010. Diversity of diatrypaceous fungi associated with grapevine canker diseases in California. Mycologia 102:319-336.

White, T. J., Bruns, T., Lee, S., and Taylor, J. 1990. Amplification and direct sequencing of fungal ribosomal RNA genes for phylogenetics. Pages 315-322 in: PCR Protocols, a guide to methods and applications. M. A Innis, D. H. Gelfand, J. J. Sninsky, and J. White, eds. Academic Press, San Diego. 